\title{
Knowledge, attitudes and practices of contact lens use in a South African adolescent population
}

\author{
Nduduzo Khoza, Therisha Moodley, Sinenhlanhla Sokhulu, Ntombethemba O Sotyana, \\ Aneesa Suliman, Rekha Hansraj, Diane van Staden
}

\begin{abstract}
Discipline of Optometry College of Health Sciences University of KwaZulu-Natal Private Bag X54001
Durban 4000.
\end{abstract}

\section{Emails:}

Nduduzo Khoza-nduduzokhoza8@gmail.com;Therisha Moodley-therishamoodley@yahoo.com;Sinenhlanhla Sokhulu-sokhulusine@gmail.com; tombethemba O Sotyana-noms05@outlook.com;Aneesa Suliman-sulimananeesa@yahoo.com; Diane van Staden-wallaced@ukzn.ac.za

\begin{abstract}
Background: Contact lens usage is becoming increasingly popular amongst young people. Assessing their knowledge, attitudes and practices in relation to contact lens wear is therefore important, so that gaps in understanding or incorrect practices can be rectified to promote continued safety and success of contact lens wear.

Objectives: This study aimed to assess and describe the knowledge, attitudes and practices of contact lens wearers aged 18 to 30 years, in the greater Durban area of South Africa.

Methods: A semi-structured questionnaire was used to assess the knowledge, attitudes and practice of the participants.

Results: Two hundred and forty six participants completed the survey. Young contact lens wearers in this sample generally had poor knowledge with regards to appropriate hygiene and contact lens wear complications. Despite wearers exhibiting a positive attitude with satisfactory hand hygiene and lens cleaning practices, important aspects such as lens case hygiene, storage and lens removal practices were found to be unsatisfactory. Compliance with after-care visits was also unsatisfactory. Conclusion: There is a need for contact lens practitioners to educate young contact lens wearers regarding appropriate contact lens-related care, to promote long term ocular health and contact lens-related safety.
\end{abstract}

Keywords: contact lens use, adolescent population, South Africa.

DOI: https://doi.org/10.4314/ahs.v20i2.29

Cite as: Khoza N, Moodley T, Sokbulu S, Sotyana NO, Suliman A, Hansraj R, et al. Knowledge, attitudes and practices of contact lens use in a South African adolescent population. Afri Health Sci. 2020; 20(2): 768-774. https://doi.org/10.4314/ abs.v20i2.29

\section{Introduction}

Contact lenses $(\mathrm{C} / \mathrm{L})$, which have many uses including refractive correction, therapeutic purposes and better cosmesis, have become a preferred method of correcting refractive error among young people in various parts of the world. ${ }^{1}$ A knowledge, attitudes and prac-

\section{Corresponding author: \\ Rekha Hansraj, \\ Discipline of Optometry College of Health \\ Sciences University of KwaZulu-Natal Private \\ Bag X54001 Durban 4000 \\ Tel: +27312607089 \\ Cell: +27829284699 \\ Email: Hansrajr@ukzn.ac.za}

tices (KAP) survey is defined as "a representative study of a specific population to collect information on what is known, believed and done in relation to a particular topic". ${ }^{2}$ Knowledge refers to facts and awareness that may have been gained through experience and/or education, while attitude is described as the feelings or belief that one has towards a certain subject. ${ }^{3,4}$ Both knowledge and attitude are said to influence one's practices, that is, how one behaves in a particular situation. 4 KAP surveys are useful as they provide an informed assessment of a community or grouping, which can be used to guide the process of creating awareness around a topic of interest. ${ }^{4}$ With young people increasingly showing preference for contact lenses over spectacles, understanding their behaviors and practices in this regard is important in promoting safe usage practices for long term ocular health.

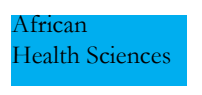

(C) 2020 Khoza N et al. Licensee African Health Sciences. This is an Open Access article distributed under the terms of the Creative commons Attribution License (https://creativecommons.org/licenses/BY/4.0), which permits unrestricted use, distribution, and reproduction in any medium, provided the original work is properly cited. 
There are several optical advantages of contact lenses over spectacles including less distortion of images, a wider field of view and a more natural visual experience ${ }^{5}$ but despite these, there are also added responsibilities that come with $\mathrm{C} / \mathrm{L}$ usage. The effective and safe use of contact lenses is dependent on an optimal fit, correct insertion and removal techniques, good hygiene and handling of lenses, amongst other factors. Good C/L practices reduce the risk of developing sight threatening infections including microbial keratitis. ${ }^{6}$ While the optimal fit is dependent on the skill and knowledge of the practitioner, usage factors depend largely on the contact lens wearers themselves where practices are often influenced by the knowledge and attitude of the C/L wearer. Several studies ${ }^{7-9}$ have reported unsatisfactory knowledge of $\mathrm{C} / \mathrm{L}$ wearers in relation to potential $\mathrm{C} / \mathrm{L}$ complications. Unhygienic practices such as the use of tap water to rinse contact lenses, suggest low levels of knowledge about the risk of Acanthamoeba infections associated with this $\mathrm{C} / \mathrm{L}$-related practice ${ }^{7,8}$. These findings indicate the need for increased education of wearers about $\mathrm{C} / \mathrm{L}$-related care and complications. Inadequate $\mathrm{C} / \mathrm{L}$ practices include a significant percentage (between $9.05 \%$ to $22.4 \%$ ) of patients over-wearing and/or sleeping with their contact lenses in the eye, as well as unsatisfactory hand hygiene and general contact lens care practices. ${ }^{7-9}$ Wongkrajang and Neeser et al. ${ }^{10}$ reported that levels of satisfactory compliance practices amongst university students were associated with age, gender, level of study and monthly income.

Most of the previous studies in this area ${ }^{5,7,11}$ assessed only knowledge and practices of $\mathrm{C} / \mathrm{L}$ wearers with only one study 8 having assessed the attitudes of $\mathrm{C} / \mathrm{L}$ wearers but that study did not report explicitly on the findings. It is important to assess attitude relating to contact lens use as this will give an indication of preconceived ideas and beliefs about contact lenses. South Africa has a growing middle class population which is increasing the demand for contact lens use amongst young people in general, it is important that the knowledge, attitudes and practices of this grouping be assessed so that any misinformation is correctd and appropriate interventions are designed to improve knowledge, attitudes and healthcare practices in this regard. This study therefore aimed to assess the knowledge, attitudes and practices of young adult $\mathrm{C} / \mathrm{L}$ wearers in the greater Durban area of South Africa.

\section{Methods}

The study employed a quantitative, descriptive cross-sec- tional design using a semi-structured questionnaire that was designed for the study. The study population consisted of contact lens wearers (soft and rigid contact lens wearers), aged between 18-30 years. Consultation with a statistician revealed that the minimum sample size required was 375 . Non-probability purposive sampling was applied to recruit $450 \mathrm{C} / \mathrm{L}$ wearers of both genders, and all races from the University of KwaZulu Natal (UKZN). Participants were also recruited from ten optometric practices in the greater Durban area and in this case the questionnaire was handed to the participant by the attending optometrist. The questionnaire was taken on paper irrespective of the site of completion. Contact lens wearers working or studying in the optometric field were excluded. Ethical clearance was obtained from the Humanities and Social Sciences Research and Ethics Committee (HSS/0390/017U). A pilot study was conducted, and the questionnaire modified for any ambiguity. Thereafter, 450 questionnaires were distributed to $\mathrm{C} / \mathrm{L}$ wearers by the researchers via participating optometry practices and also at the UKZN.

Questionnaires were available in English and isiZulu, the predominant languages of the region concerned. The questionnaire was self-administered but the researchers were available for any queries. The questionnaire included the demographic profiles of participants and questions relating to knowledge of the respondents regarding hygiene, $\mathrm{C} / \mathrm{L}$ solutions and $\mathrm{C} / \mathrm{L}$ wear complications. The attitudes of the respondents were assessed using a five point Likert scale that ranged from strongly agree to strongly disagree. Statements were in the subcategories of hygiene, compliance, aftercare, $\mathrm{C} / \mathrm{L}$ and solution handling and $\mathrm{C} / \mathrm{L}$ wear complications. The respondents' ratings of the various statements were used to assess their level of enthusiasm and overall feeling/ attitude. The last section of the questionnaire assessed practices with respect to wearing modality, hygiene, $\mathrm{C} / \mathrm{L}$ and solution handling, and $\mathrm{C} / \mathrm{L}$ wear complications.

\section{Data analysis}

Data was captured and analyzed using the Statistical Package for Social Sciences (SPSS v.24). Descriptive statistics and frequency counts in percentage was used to present the findings. The chi-squared test was used to investigate associations at a $95 \%$ confidence level.

\section{Results}

Of the 450 questionnaires distributed, 247 were returned giving a response rate of $54.8 \%$. The ages of respondents ranged from 18 to 30 years with a mean age 
of $23.9 \pm 3.9$ years. The majority of respondents were female $(62.8 \%)$, of Indian descent $(53.8 \%)$ and had been contact lens wearers for more than one year $(72.2 \%)$. The majority of respondents $(90.7 \%)$ were soft contact lens wearers and the most prevalent wearing modality was monthly disposable soft lenses $(63.8 \%)$ followed by daily wear $(22 \%)$, two weekly $(3.3 \%)$, yearly $(2.8 \%)$ and the remainder $(8.1 \%)$ a combination..

\section{Knowledge}

About half $(49 \% ; \mathrm{n}=121)$ of the respondents were aware of the brand name of their $\mathrm{C} / \mathrm{L}$, and of these only $43.7 \%(n=108)$ replaced their lenses according to the manufacturer recommended replacement frequency (MRRF). Knowledge of brand of contact lenses was found to be significantly associated with race $\left(\chi^{2}=\right.$ $16.89 ; \mathrm{p}=0.01)$.

Just above half $(51.8 \% ; \mathrm{n}=128)$ of the respondents knew that the main reason for cleaning contact lenses was to reduce the risk of infections. However, a few $(5.7 \% ; \mathrm{n}=14)$ were aware that proper cleaning also aids in the removal of debris off the lens surface which is related to the finding that less than half $(40 \% ; n=$ 98) of the respondents felt that rubbing of the contact lenses during cleaning was necessary. While the majority $(86.8 \% ; \mathrm{n}=211)$ were aware of multi-purpose solutions (MPS) as an appropriate cleaning and disinfection solution, only $10.9 \%(n=25)$ of respondents had knowledge of peroxide based cleaning solutions. Saline and water were reported as acceptable cleaning solutions by $10.3 \%(n=29)$ and $3.6 \%(n=5)$ of respondents, respectively.

The majority $(60.5 \% ; \mathrm{n}=132)$ correctly identified corneal ulcers as a possible complication of C/L non-compliance, however $8.3 \%(n=19)$ of the respondents believed cataracts to be a complication also. Only one in five respondents $(20.9 \%$; $=51)$ were aware that contaminated, over-worn and torn lenses could possibly lead to contact lens-related complications, while $17 \%$ $(n=42)$ reported that symptoms of possible complications from contact lens wear included ocular itching, discharge and pain.

\section{Attitudes}

The majority $(77.7 \% ; \mathrm{n}=192)$ of respondents believed that they were competent $\mathrm{C} / \mathrm{L}$ wearers (Table 1) with the older respondents more likely to consider themselves as competent contact lens wearers $\left(\chi^{2}=68.496\right.$; $p=0.002)$. While most of the respondents felt that the cleaning of contact lenses and contact lens cases were necessary $(94.4 \% ; \mathrm{n}=233$ and $77.3 \% ; \mathrm{n}=191$, respectively), $34.9 \%(\mathrm{n}=86)$ felt that washing of hands prior to $\mathrm{C} / \mathrm{L}$ handling was unnecessary. Almost one-third $(32 \% ; n=79)$ of the respondents believed that regular aftercare follow-up visits to the optometrist should be optional. Despite the concerning attitudes towards hand hygiene and aftercare visits, 58.2\% $(\mathrm{n}=146)$ felt that contact lenses should be replaced according to the wearing schedule and not necessarily only relating to the comfort level.

Table 1: Attitudes of respondents towards $\mathrm{C} / \mathrm{L}$ practices

\begin{tabular}{|c|c|c|c|c|c|}
\hline & $\begin{array}{l}\text { Strongly } \\
\text { Agree }\end{array}$ & Agree & Neutral & Disagree & $\begin{array}{l}\text { Strongly } \\
\text { Disagree }\end{array}$ \\
\hline I am a competent $\mathrm{C} / \mathrm{L}$ wearer & $28.8 \%$ & $49.50 .2 \%$ & $17.7 \%$ & $3.3 \%$ & $1.60 \%$ \\
\hline Cleaning $\mathrm{C} / \mathrm{L}$ is necessary & $64.4 \%$ & $30.0 \%$ & $5.3 \%$ & $0.4 \%$ & $0 \%$ \\
\hline Cleaning case is necessary & $49.4 \%$ & $27.9 \%$ & $13.0 \%$ & $8.9 \%$ & $0.8 \%$ \\
\hline $\begin{array}{l}\text { Washing of hands is unnecessary when } \\
\text { handling } \mathrm{C} / \mathrm{L}\end{array}$ & $20.3 \%$ & $14.6 \%$ & $6.5 \%$ & $33.7 \%$ & $24.8 \%$ \\
\hline Follow up visits should be optional & $7.8 \%$ & $24.5 \%$ & $18.4 \%$ & $34.5 \%$ & $14.8 \%$ \\
\hline $\begin{array}{l}\text { Replacement of } \mathrm{C} / \mathrm{L} \text { based on comfort } \\
\text { level }\end{array}$ & $8.9 .0 \%$ & $22.4 \%$ & $8.6 \%$ & $38.4 \%$ & $21.2 \%$ \\
\hline
\end{tabular}

\section{Practice}

The majority $(71.3 \%)$ of respondents employed an effective and thorough method of cleaning their hands prior to $\mathrm{C} / \mathrm{L}$ handling, which involved utilizing water and soap $(73.3 \% ; \mathrm{n}=181))$ while $10.9 \%(\mathrm{n}=27)$ utilized hand sanitizer only. More than half $(58.7 \% ; \mathrm{n}=$
145) of respondents reported complying with the instructions given to them by their optometrist. Contact lenses were cleaned on a daily basis by the majority $(77.2 \% ; \mathrm{n}=190)$ of the respondents (Figure 1), with the frequency of cleaning being significantly associated with wearing schedule $\left(\chi^{2}=39.013 ; \mathrm{p}=0.03\right)$. 


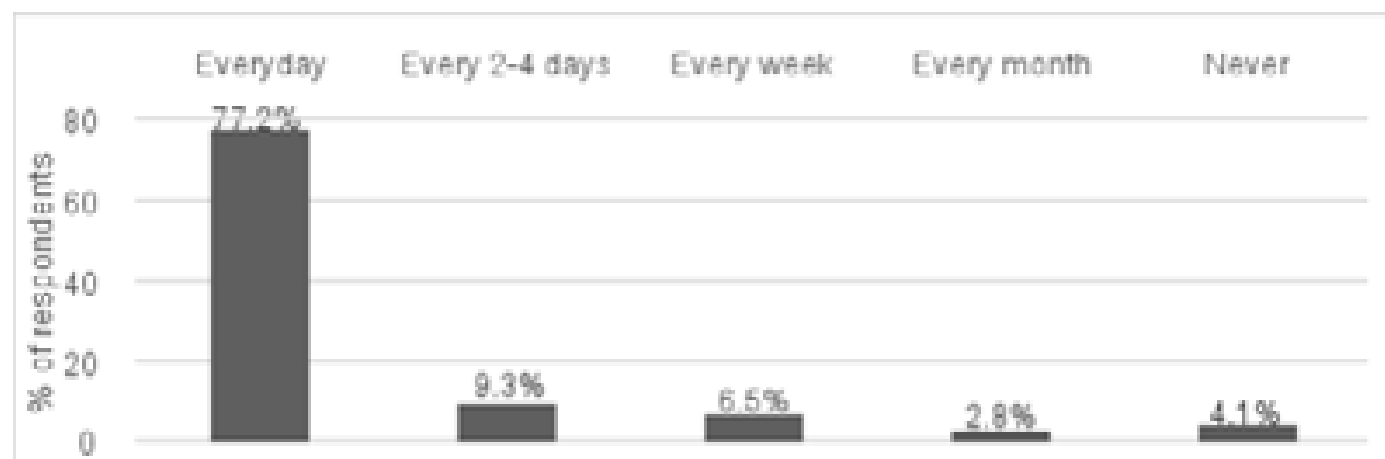

Figure 1: Frequency of cleaning of contact lenses

A few $(24.1 \% ; n=58)$ of the respondents cleaned their $\mathrm{C} / \mathrm{L}$ cases daily, with no association between case hygiene and the wearing schedule $\left(\chi^{2}=28.764 ; \mathrm{p}=0.23\right)$. However, $92 \%(n=226)$ of the respondents utilized the correct method of cleaning cases which entailed the use of disinfecting solution to wash the case, including a rubbing action, and then leaving the case to air-dry. Less than half $(42.9 \% ; \mathrm{n}=105))$ reported replacing the solution in their cases daily, and even fewer $(28.2 \%$; n $=68$ ) replaced their $\mathrm{C} / \mathrm{L}$ cases monthly. No association was foundbetween $\mathrm{C} / \mathrm{L}$ solution renewal and the wearing schedule $\left(\chi^{2}=25.969 ; \mathrm{p}=0.36\right)$. Just over one-third $(34.4 \% ; n=85)$ of respondents wore their contact lenses for more than eight hours per day, while $41.7 \%$ (103) admitted to sleeping with their contact lenses on.

With regards to the use of make-up, 37.4\% ( $\mathrm{n}=76)$ of the respondents applied make-up after $\mathrm{C} / \mathrm{L}$ insertion and removed make-up before removal of $\mathrm{C} / \mathrm{L}$, which is the correct order of application. While $59.8 \%(n=147)$ utilized the correct insertion method, that is, removing the $\mathrm{C} / \mathrm{L}$ from the solution, rinsing it and then verifying the orientation of the C/L before insertion, 39\% ( $\mathrm{n}=$ 96) were neither disinfecting nor checking that the lens was on the correct side before insertion. With regards to the removal of the lens, less than half $(44.3 \%$; $n=$ 108) of the respondents were sliding their soft lens off the cornea before taking it out of the eye.

Approximately two-thirds $(68 \% ; \mathrm{n}=168)$ of the respondents were aware of any aftercare visits scheduled by their optometrist and $46.2 \%(n=114)$ of those that were aware of aftercare visits booked were compliant in their attendance. Some $(18.6 \% ; n=46)$ of the respondents had never experienced any C/L-related com- plications but $21.1 \%(\mathrm{n}=52)$ reported that they would definitely continue $\mathrm{C} / \mathrm{L}$ wear should symptoms of a potential complication arise, while $44.9 \%(\mathrm{n}=111)$ reported that they would cease $\mathrm{C} / \mathrm{L}$ wear in this event. Just more than one-third $(30.6 \% ; n=75)$ of the respondents admitted that they would not seek out medical help in the event of a symptom occurring.

\section{Discussion}

This study set out to explore the knowledge, attitudes and practices of young adult $\mathrm{C} / \mathrm{L}$ wearers in a South African population. The findings of the study highlight that good practice with $\mathrm{C} / \mathrm{L}$ wear is dependent on adequate patient instruction. Overall, the knowledge of respondents in this study, in relation to $\mathrm{C} / \mathrm{L}$ use, was found to be inadequate. Knowledge of $\mathrm{C} / \mathrm{L}$ brand names and their corresponding wearing schedules amongst wearers was lacking. This type of knowledge may have been influenced by educational status but this relationship was not assessed in this study. This is similar to the findings of Donshik et al. ${ }^{12}$ and may partly account for the noncompliance reported with regards to $\mathrm{C} / \mathrm{L}$ wearing schedules. Following the correct $\mathrm{C} / \mathrm{L}$ wearing schedule is important, as a lens is designed to be durable for a specified amount of time only.

Of concern was that a large number of respondents also lacked knowledge of the correct methods of cleaning contact lenses. Cho et al. ${ }^{13}$ reported that not rubbing a contact lens during cleaning is ineffective in removing loosely bound deposits. Deposits that adhere to the surface of a contact lens support the growth of biofilms, andtherefore encourage adherence of microbes which could lead to sight threatening infections. ${ }^{14}$ Respondents were also unaware of the purpose of cleaning their 
contact lenses, which potentially impacts on their compliance with recommended cleaning regimes. Furthermore, ensuring contact lens hygiene depends not only on the method of cleaning but also the choice of solution. Hydrogen peroxide $\mathrm{C} / \mathrm{L}$ cleaning solutions have been reported to be provide superior benefits over MPS solutions, ${ }^{14,15-19}$ yet the majority of respondents were unaware of this type of $\mathrm{C} / \mathrm{L}$ solution which may imply that they are not being informed about all possible cleaning options by their optometrists.

Adequate knowledge of $\mathrm{C} / \mathrm{L}$ complications, which is linked to knowledge about the cleaning of contact lenses, could possibly motivate wearers to be more vigilant in this regard. However, this study found that there was a lack in knowledge with regards to the common ocular symptoms associated with C/L-related complications, in keeping with the findings of Mahadevan et al. ${ }^{8}$ The fact that there was poor knowledge in this regard, suggests that awareness of pertinent symptoms could ensure that $\mathrm{C} / \mathrm{L}$ wearers seek medical treatment timeously, which in turn impacts on the prognoses. ${ }^{20}$

While knowledge is acquired, attitudes aremore ingrained and significantly influences practice.4 Similar to the report by Ndedi, ${ }^{21}$ respondents in this study believed that they were competent $\mathrm{C} / \mathrm{L}$ wearers. However, the poor attitudes towards hand washing prior to handling of contact lenses were similar to the findings of previous studies ${ }^{10,22}$ which is concerning since hand hygiene is important in reducing the occurrence of contact lens contamination. McMonnies ${ }^{23}$ asserted that better attitudes toward hand hygiene with contact lens use are required to reduce high levels of noncompliance. Furthermore, a poor attitude towards adhering to follow-up appointments with their optometrists found in this study is also concerning, as these follow up appointments are important for ensuring good ocular health, preservation of vision and the early diagnosis and intervention in the event of contact lens-related complications. In this regard, eye care practitioners need to educate their contact lens patients on the importance of follow up or aftercare visits.

Despite the finding of poor attitudes with respect to hand hygiene in this study, respondents generally had good practice with regards to hand washing, using the preferred method of soap and water. This is supported by findings of Liu et al. ${ }^{24}$ which concluded that antibacterial soaps are more effective than hand sanitizers. Ar- eas of concern regarding the handling of contact lenses in this study included insertion and removal practices and make-up use in conjunction with $\mathrm{C} / \mathrm{L}$ wear. Incorrect handling methods regarding the use of make-up with contact lenses have been found to contribute to possible deformation of the $\mathrm{C} / \mathrm{L}$, in addition to contamination..$^{25}$ This may be an area that optometrists often overlook, particularly with female patients.

Contrary to the good hand hygiene practices in this study, unsatisfactory $\mathrm{C} / \mathrm{L}$ case hygiene practices were found which is similar to the findings of Ndedi. ${ }^{21}$ While respondents appeared to be using the correct method of cleaning their contact lens cases, they did notlean their cases or replace the solution in their cases regularly. This is of concern, as poor case hygiene has been identified as one of the leading risk factors for microbial keratitis in contact lens wearers. ${ }^{26}$ Adherence to the correct wearing schedule is also important in avoiding unwanted C/L-related complications, and in general an average wearing time of eight hours is recommended. In this study, at least one in three respondents exceeded this recommendation. Mahadevan et al. ${ }^{8}$ also found that approximately one in every four $\mathrm{C} / \mathrm{L}$ wearers wore their lenses for between 10-15 hours. While silicone hydrogel, which is the most commonly used material for soft contact lenses ${ }^{27}$ allows for longer wearing time due to its higher oxygen permeability, Fowler et al. ${ }^{28}$ reported that the amount of deposits in high water content lenses worn for eight hours or more resemble that found after two months of extended wear. Therefore, in order to maintain good lens optics and ocular health, lenses should be worn for the prescribed amount of time and patients should avoid overwear practices, including sleeping with their contact lenses which was a significant finding in this study. This finding is different to that of Mahadevan et al. ${ }^{8}$ and Alasiri et al. ${ }^{9}$ who found a slightly lower percentage of respondents sleeping with their lenses. Sleeping while wearing contact lenses also has serious implications for ocular health and studies have shown that the cornea is more susceptible to infiltration and microbial keratitis associated with nocturnal hypoxia when sleeping with contact lenses. ${ }^{29,30}$ The way in which one responds to the early signs of a microbial keratitis or any other contact lens complication is important, as this could determine the course and severity of the complication. Medical attention should be sought immediately, yet only a small percentage of respondents stated that they would seek immediate medical assistance if they experienced any symptoms of potential C/L complications. 
Compliance with follow-up appointments could also potentially reduce the occurrence of contact lens complications, as ocular health and vision are usually assessed, and changes monitored. In addition, wear and care practices should be reviewed and corrected during these sessions. The inadequate compliance rate with aftercare visits found in this study is similar to findings reported in other studies ${ }^{22,31}$ highlighting the importance of patient education in this regard.

While the findings of this study were based on subjectively-reported responses which can sometimes be influenced by untruthfulness, there is sufficient cause for concern with regards to the existing knowledge, attitudes and practices of young contact lenses wearers in this study population. However, while a minimum sample size of 375 was required, only 247 completed questionnaires were included in the analysis due to time constraints which limits generalization of the results. The majority of the findings suggest a lack of appropriate information with regard to correct contact lens-related usage practices. This suggests that more needs to be done on the part of optometrists or other clinicians dispensing contact lenses, to educate patients on appropriate handling, usage, storage and long term healthy usage practices. In cases where non-clinical staff are involved in the dispensing of contact lenses to patients, it is important that they too are properly informed and trained for this important role. Of interest would be to explore whether findings would be similar in an older or more diverse age-range study sample, to assess if maturity and experience alters the aspects under investigation in this study. The findings of this research provides a baseline understanding of the knowledge, attitudes and practices of young adult contact lens wearers in South Africa and outlines the key areas for improvement. While the study focused on youth, these results could be used to inform continuing practitioner development activities as well as health education and promotion interventions with regards to healthy contact lens use and practices amongst contact lens wearers generally.

While this study highlighted the gaps in knowledge of young contact lens wearers in the greater Durban area, more needs to be done to improve the knowledge, attitudes and practices of contact lens wearers in general, since similar findings of concern were noted in other parts of the world. Therefore, more effort should be directed toward appropriately educating contact lens wearers in order to improve their knowledge, attitudes and practices in relation to $\mathrm{C} / \mathrm{L}$ usage.

\section{References}

1. Janti S, Charanya C, Raja AM, Matheen A, Pandurangan R. Knowledge, attitude and practices of contact lens users among medical students in Tamil Nadu. Int J Sci Stud. 2014;2:20-23.

2. World Health Organization. Advocacy, Communication and Social Mobilization for TB control / A guide to developing knowledge, attitude and practice surveys. 2008. WHO/HTM/STB/2008.46. Available from: http://apps.who.int/iris/bitstream/ handle/10665/43790/9789241596176_eng.pdf;jsessionid=A6FD1C569B5B9DE5FB6C0A71AB5AAB4F? sequence=1 Accessed November 24, 2018.

3. Oxford paperback dictionary and thesaurus. Oxford: New York: Oxford University Press; 2009.

4. Kaliyaperumal K. Guidelines for conducting a knowledge, attitude and practice (KAP) study. AECS Illumination. 2004;4:7-9.

5. Giri PA, Chavan WM, Phalke DB, Bangal SV. Knowledge and practice of contact lens wear and care among contact lens users medical students of rural medical college, Loni, Maharashtra, India. Int J Biol Med Res. 2012;3:1385-1387.

6. Suchecki JK, Donshik P, Ehlers WH. Contact lens complications. Ophthalmol Clin North Am. 2003;16:47184.

7. Tajunisah I, Reddy SC, Phuah SJ. Knowledge and practice of contact lens wear and care among medical students of University of Malaya. Med J Malaysia. 2008;63:207-210.

8. Mahadevan G, Arunkumar S, Srushti DS, Suranagi P. Ocular health education - Knowledge, attitude and practice of contact lens usage among medical students. J Educ Res Med Teach. 2014; 2:26-28.

9. Alasiri RA, Alqulayti WM, Neama SH, Alsulami IA, Bawazeer AM. Practice and knowledge of contact lens wear and care among female medical college students in Kingdom of Saudi Arabia. Int J Biol Med Res. 2015;6:5240-5242.

10. Wongkrajang P, Neeser KJ. Knowledge, attitude, practice and eye problems from contact lens use in students at Chulalongkorn University 2010. J Health Res. 2012; 26:113-118.

11. Robertson DM, Cavanagh HD. Non-compliance with contact lens wear and care practices: a comparative analysis. Optom Vis Sci. 2011;88:1402-1408.

12. Donshik PC, Ehlers WH, Anderson LD, Suchecki JK. Strategies to better engage, educate, and empower patient compliance and safe lens wear: Compliance: What we know, what we do not know, and what we need to know. Eye Contact Lens. 2007;33:430-433. 
13. Cho P, Cheng SY, Chan WY, Yip WK. Soft contact lens cleaning: rub or no-rub?. Ophthalmic Physiol Opt. 2008;29:49-57.

14. Kal A, Toker MI, Kaya S. The comparison of antimicrobial effectiveness of contact lens solutions. Int Opbthalmol. 2017;37:1103-1114.

15. Niszl IA, Markus MB. Anti-Acanthamoeba activity of contact lens solutions. Brit J Ophthalmol. 1998;82:1033-1038.

16. Kobayashi T, Gibbon L, Mito T, Shiraishi A, Uno T, Ohashi Y. Efficacy of commercial soft contact lens disinfectant solutions against Acanthamoeba. Jpn J Ophthalmol. 2011;55:547-557.

17. Shoff ME, Joslin CE, Tu EY, Kubatko L, Fuerst PA. Efficacy of contact lens systems against recent clinical and tap water Acanthamoeba isolates. JCED. 2008;27:713-719.

18. Reverey JF. Fromme R, Leippe M, Selhuber-Unkel

C. In vitro adhesion of Acanthamoeba castellanii to soft contact lenses depends on water content and disinfection procedure. Cont Lens Anterior Eye 2014;37: 262 266.

19. Artini M, Cellini A, Scoarughi GL, Papa R, Tilotta M, Palma $S$ et al. Evaluation of contact lens multipurpose solutions on bacterial biofilm development. Eye Contact Lens 2015;41: 177-182. DOI: 10.1097/ ICL.0000000000000105.

20. Loh KY, Agarwal P. Contact lens related corneal ulcer. Malays Fam Physician. 2010; 5: 6-8. PubMed.

21. Ndedi SB. Analysis of patient practices and attitudes towards compliance with contact lens storage cases in relation to microbial contamination levels, Fort Worth, Tx: University of North Texas Health Science Center [homepage on the Internet]. c2015 [cited 2017 Oct 12]. Available from: http://digitalcommons.hsc.unt.edu/ theses/848 Accessed January 31, 2017.

22. Wu Y, Carn, N, Stapleton F. Contact lens user pro- file, attitudes and level of compliance to lens care. Cont Lens Anterior Eye. 2010;33:183-188.

23. McMonnies CW. Hand hygiene prior to contact lens handling is problematic. Cont Lens Anterior Eye. 2012;35:65-70.

24. Liu P, Yuen Y, Hsiao H, Jaykus L, Moe C. Effectiveness of liquid soap and hand sanitizer against Norwalk Virus on contaminated hands. Appl Environ Microbiol. 2010;97:394-399.

25. Tsukiyama J, Miyamoto Y, Fukuda M, Shimomura Y, Tsuchiya J, Miura H. Influence of cosmetic and cleansing products for the eyes on soft contact lenses. Invest Ophthalmol Vis Sci. 2009; 50(13). Online article Available from: https://iovs.arvojournals.org/article.aspx?articleid $=2368008$. Accessed September 22, 2017.

26. Dyavaiah M, Ramani R, Chu DS, Ritterband CD, Shah MK, Samsonoff WA et al. Molecular characterization, biofilm analysis and experimental biofouling study of Fusarium isolates from recent cases of fungal keratitis in New York State. BMC Ophthalmol. 2015;7:123-128. 27. Heiting G. Silicone hydrogel contact lenses. All about vision. Accessible from: https://www.allaboutvision.com/contacts/silicone-hydrogel.htm. Accessed October 20, 2018.

28. Fowler SA, Korb DR, Allansmith MR. Deposits on soft contact lenses of various water contents. CLAO J. 1985;11920:124-127.

29. Goodlaw E. Risk of infection from sleeping with contact lenses on: causes of risk. Optom Vis Sci. 1996;73:156-158.

30. Tariq F, Koay P. The risk of contact lens wear and the avoidance of complications. Int J Med Stud. 2013;1:80-85.

31. Chattu VK. Importance of compliance in contact lens wear - a study to assess the knowledge and practices among contact lens users for a healthy vision. Int J Curr Res Rev. 2013;5:104-109. 